Grundtvigs tænkning, der er fremmede for os i dag. Det er vigtigt. Man må også give hende ret $\mathrm{i}$, at man ikke bare i apologetisk interesse må bortinterpretere disse sider. Men derfor er det dog ikke illegitimt at tage opgaven op, at aktualisere og dermed $n y$ eller ominterpretere Grundtvig. Kan være, at Grundtvigs tale om modersmålet og folk hos ham selv meget mere snævert var ment som en metafysik om det danske sprogs og den danske kulturs overlegenhed - men virkningshistorien - og netop også den internationale højskolebevægelse - viser, at det kan være legitimt at tolke Grundtvig i universel og almenmenneskelig forstand. Kan være, at Grundtvig i sit digt Menneske først i virkeligheden mente Dansker først, men det må være tilladt at tolke netop dette digt universelt. Og at den smukke pinsesalme Var I ikke Galilaeer især taler om, at Ånden særligt lever i det danske modersmål (v. 3, se s. 74, note 311), var måske Grundtvigs intention, men det gør ikke en universel tolkning af salmen umulig. Skal ikke enhver aktualiserende interpretation, om det nu er Luther, Kierkegaard eller Grundtvig, skelne mellem det, der er tidsbestemt hos en forfatter og fremmed for os, og det, der kan aktualiseres? Og selv i en mere immanent Grundtviginterpretation skal der tages hensyn til, hvilken kontekstuel vaegt de af bogen påviste problematiske aspekter har hos Grundtvig. Man må ikke bortfortolke de "totalitære« træk hos Grundtvig, men man bør heller ikke overfortolke dem, som om Grundtvig kun har tænkt på den danske kulturs og det danske sprogs overlegenhed, når han talte om folk og modersmål. Man risikerer ellers at tabe de progressive sider af den grundtvigske arv af syne. Så entydig er sagen formentlig ikke: Også den "venstreorienterede« og progressive Grundtvigreception kan påberåbe sig tekster hos Grundtvig.

Uanset, hvordan det forholder sig: Til trods for bogens tese om autoritære og totalitære træk hos Grundtvig er jeg af den opfattelse, at Grundtvig i dag ikke kun kan tåle kritik og modsigelse, men ligefrem også har brug for det. Grundtvig er formentlig mere tjent med kritisk opmærksomhed end med plat apologetik. Derfor: En vigtig og værdifuld bog!

\title{
Freiheitliche Rhetorik und totalitäre Tendenzen Wahre Aufklärung und Dänentum bei Grundtvig
}

\section{Von Eberhard Harbsmeier}

Inga Meincke: Vox Viva. Die »wahre Aufklärung« des Dänen Nikolaj Frederik Severin Grundtvig, Skandinavische Arbeiten Band 17, Universitätsverlag C. Winther, Heidelberg 2000, 371 Seiten.

Es gibt, soweit ich orientiert bin, nur wenige wirklich kritische Auseinandersetzungen mit Grundtvig in der Grundtvigliteratur und Grundtvigforschung. Vor allem die ausländische Literatur über Grundtvig ist geprägt von mehr oder weniger unkritischer Bewunderung für Grundtvig, die problematischen und für den heutigen Leser inak- 
zeptablen Seiten des Grundtvigschen Denkens werden dabei entweder umgedeutet oder verdrängt. Dabei entsteht ein Grundtvigbild, eine Art Exportausgabe, die ihn in einem progressiven Lichte erscheinen läßt, als Schöpfer des modernen Dänemark, der in einzigartiger Weise christliche Tradition und Freiheitsliebe der Moderne miteinander $\mathrm{zu}$ verbinden vermochte und indirekt mitverantwortlich ist für das moderne freiheitliche Modell des dänischen Wohlfahrtsstaates. Grundtvig, so die gängige Auffassung, sei es zu verdanken, daß Begriffe wie Volk und Volkheit in Dänemark einen guten Klang haben und nicht zu einem aggressiven Nationalismus gefuhrt haben wie in anderen Ländern bzw. vor allem in Deutschland.

Die Dissertation von Inga Meincke rüttelt gründlich an diesem Bilde. Sie sieht hinter der freiheitlichen Rhetorik Grundtvigs »nationalistische« (auch wenn sie diesen Ausdruck meidet) und autoritäre Tendenzen, die Grundtvigsche Bewegung war zunächst keine Volksbewegung, sondern eine esoterische Sekte mit einem autoritären Führer, um den ein geradezu mythischer Personenkult veranstaltet wurde. Grundtvig war ein autoritärer Gegenaufklärer, der keinen Widerspruch duldete, der visionär »im Namen des Lebens« sprach, statt zu argumentieren und zum Gespräch anzuregen. Grundtvig entzieht sich, so der Vorwurf Inga Meinckes an die Grundtvigrezeption, der kritischen Auseinandersetzung. Wer kritisch ist, offenbart nur, daß er sich nicht angemessen in die Welt Grundtvigs »eingelebt habe«:

Für kritische Auseinandersetzung ist hier kein Raum. Das Wissenschaftsverdikt bedeutet Verzicht auf Nachvollziehbarkeit, auf intersubjektive Geltung und auf Kritik, die sich immer dem Vorwurf ignoranter Rezeption ausgesetzt sieht (S. 28).

Grundtvig als reaktionärer, antirationalistischer und nationalistischer Gegenaufklärer - dieses Grundtvigbild, das übrigens auch das der ersten ausländischen Zeitgenossen Grundtvigs war, erklärt zur Genüge, warum Grundtvig international nicht die Beachtung gefunden hat wie z.B. H.C. Andersen oder Søren Kierkegaard. Und auch die "progressive« Wirkungsgeschichte Grundtvigs in Dänemark wird als weitgehendes Mißverständnis entlarvt.

II

Es handelt sich bei der Arbeit Inga Meinckes freilich keineswegs um reine Polemik, sondern um eine außerordentlich materialreiche, gründliche und informative Dissertation, die nach einer ausführlichen Einführung, die die Wirkungsgeschichte im Inund Ausland darstellt, in drei Schritten, die biographisch gegliedert sind, den Grundtvigschen Begriff der Aufklärung analysiert. Dabei kommen Grundtvigs Auffassung von Geschichte, seine Auseinandersetzung mit dem Rationalismus, sein Konzept der "Volkheit« bzw. des Dänentums, seine Lehre vom »lebendigen Wort» und das Konzept einer »volklichen Hochschule« zur Sprache. Es handelt sich um eine literaturwissenschaftliche Arbeit, bei der weniger die theologischen und pädagogischen Schriften Grundtvigs im Mittelpunkt stehen als sein literarisches Werk. Auch für den, der die kritische Sicht der Autorin nicht teilt, eine imponierende Leistung - kritisch, aber nicht gehässig, und sachlich außerordentlich informativ geschrieben, fast mit einer Überfülle an Material. Inga Meincke widersteht trotz aller Kritik der 
Versuchung, nun einfach in platter Weise Grundtvig mit nationalistischer Blut und Boden Ideologie in Verbindung zu bringen oder gar als Präfaschisten entlarven zu wollen.

III

Was Inga Meincke an Grundtvig mißfällt, sind - soweit ich sehen kann - vor allem zwei oft verdrängte Züge im Denken Grundtvigs: Grundtvigs visionäre Theorie von echter Aufklärung und dem »lebendigen Wort« ist erstens zutiefst autoritär und totalitär und zweitens unlösbar verknüpft mit einer metaphysischen Idee von der Überlegenheit der dänischen Sprache und Kultur, also dem Grundtvigschen "Nationalismus«.

Ich wende mich zuerst dem zweiten zu, Grundtvigs metaphysischen Auffassung. vom Dänentum.

Ich möchte zur Einführung in die Diskussion um den Grundtvigschen »Nationalismus « mit einer deutschen Erfahrung beginnen: In meiner Schulzeit an einem deutschen Gymnasium der Nachkriegszeit hatten wir einen Geschichtslehrer, der, um es vorsichtig zu sagen, recht »deutsch-national« gesinnt war. Ich war linksliberal erzogen und deshalb in permanenter Opposition gegen dessen deutsch-nationalen Geschichtsunterricht. Ein Lieblingsstreitpunkt war das Deutschlandlied, das für mich als Nationalhymne völlig inakzeptabel war, am besten wäre es meiner Ansicht nach gewesen, diese Hymne ganz abzuschaffen, mir schien es ein schlechter Kompromiß und eine Zumutung für andere Völker, die Hymne beizubehalten, aber nur die dritte Strophe zu singen.

Mein Geschichtslehrer hatte da natürlich eine ganz andere Auffassung: Man dürfe, so die gängige Version, das Deutschlandlied nicht nationalistisch mißverstehen, so wie dies im Nationalsozialismus geschehen sei, das Deutschlandlied behaupte nicht die Überlegenheit des Deutschtums über andere Völker im nationalistischen Sinne, sondern singe von der legitimen Liebe zum eigenen Vaterland, die durchaus mit dem Respekt für andere Völker vereinbar sei. Es müsse eigentlich heißen: Deutschland lieb'ich über alles! Nach diesem richtigen Verständnis sei der Text eigentlich akzeptabel als Ausdruck natürlicher Vaterlandsliebe.

Ich habe an diese gängige Erklärung nicht geglaubt, ich glaube heute weniger denn je an derartige Versuche, Nationalismus zu verniedlichen und zu verharmlosen.

Die Dänen haben gottlob kein Deutschlandlied - aber sie haben Grundtvig und das grundtvigsche Erbe. Die Rezeptionsgeschichte des Grundtvigschen »Nationalismus«, so wie sie in der Heidelberger Dissertation von Inga Meincke dargestellt wird, ähnelt etwas der oben genannten verharmlosenden Interpretation des Deutschlandliedes: Man singt nur die dritte Strophe, d.h. deutet Grundtvigs Reden von Volk und Dänentum universalistisch bzw. allgemeinmenschlich, und man verharmlost die «nationalistischen« Seiten Grundtvigs, die es natürlich auch gibt, als sozusagen netten und nicht aggressiven Patriotismus, der angeblich mit dem Nationalismus anderer Völker nicht $\mathrm{zu}$ vergleichen sei. Grundtvig habe, so die gängige Auffassung, den Nationalismus geläutert und damit akzeptabel gemacht. Die problematischen "nationalistischen« Passagen im Werk Grundtvigs werden dabei ausgeblendet, verdrängt, oder, wo dies nicht möglich ist, verharmlosend umgedeutet. Dabei kann es, so Meincke, auch heute 
in der Grundtvigrezeption zu einer sublimen Form von ethnizistischen Auffassung von der Überlegenheit dänischer Kultur kommen, wonach (vielleicht mit Ausnahme von Holland) nur in Dänemark die Demokratie natürlich sei, die Bürgerrechte respektiert würden, soziale Sicherheit angestrebt werde und Krieg als Mittel der Politik abgelehnt werden (S. 55, Anm. 205, Hinweis auf einen Artikel von Finn Slumstrup). Eine These, die sich nach Meincke »ohne metaphysische oder schlicht rassistische Anleihen « nicht halten läßt. Eine Art von sublimem skandinavischem pharisäischem Neonationalismus, der die nordischen Länder als die tolerantesten und freiheitsliebendsten der Welt ansieht - und zugleich zumindest unterschwellig gehässige Vorurteile nicht nur gegen Deutschland, sondern vor allem auch gegen romanische, angelsächsische und slawische Länder pflegt. Inga Meincke notiert z.B. die »bewußte Falschmeldung« der dänischen Zeitung Information, der Deutsche Bundestag habe nach dem Fall der Mauer 1989 die erste Strophe des Deutschlandliedes gesungen, eine Falschmeldung, die auch von der Leiterin des Schloßmuseums in Sonderburg weiter verbreitet wird (S. 58). Es handelt sich, so die Analyse, um die Wiederkehr des Verdrängten: Der "Nationalismus" Grundtvigs, den man verdrängt hat, kehrt wieder in einer mehr sublimen, aber darum nicht weniger pharisäischen Auffassung von der Überlegenheit nordischer Kultur und Demokratie.

Man muß der Verfasserin darin Recht geben: Die »nationalistischen « Äußerungen Grundtvigs sind nicht nur Einzelerscheinungen und Entgleisungen, die man als marginal abtun könnte. Wenn Grundtvig von Volk spricht, meint er das dänische Volk, wenn er von der Muttersprache spricht, meint er die dänische Sprache. Grundtvigs berühmtes Gedicht an seine Muttersprache ist $» k$ kein linguistisches, sondern ein metaphysisches Konzept« (S. 277). Nicht um traditionelle patriotische Betonung der Muttersprache geht es, sondern um eine totalitäre Metaphysik von der Überlegenheit der dänischen Sprache. Grundtvig war zutiefst davon überzeugt, daß die dänische »Herzenssprache« allen anderen Sprachen überlegen sei, wie Inga Meincke mit vielen Zitaten belegt, hierunter die schöne - sicherlich falsche - Theorie Grundtvigs, daß walles Schöne und Gute sich ins Dänische übersetzen läßt, ohne das Geringste zu verlieren, wohingegen das Beste Dänische sich in keine Sprache, nicht einmal ins Englische übersetzen läßt, ohne mindestens die Hälfte zu verlieren« (S. 43). Inga Meincke kann auch auf andere, weniger harmlose Seiten Grundtvigs verweisen, z.B. sein Konzept von Volkheit als »ethnischer Reinheit» (S. 247) und fehlender Sinn fur »multikulturelle Gleichwertigkeit«. Alles, was fremd ist, wird als undänisch bekämpft, und Grundtvig kann den Juden Goldschmidt nur als Gast, nicht aber als Teil der dänischen Gemeinschaft akzeptieren. Inga Meincke steht nicht an, Grundtvigs Argumentation gegen Goldschmidt als »perfide« zu brandmarken (S. 250f.). Die moderne Fremdenfeindlichkeit in Dänemark kann sich auf Grundtvig berufen, und schon Fontane hat 1864 von dem »blasphemischen Dogma des alten Professors Grundtvig" geredet, »daß Gott am Jüngsten Tage in dänischer Sprache zu Gericht rufen würde» (Zitat S.15). Und als Motto des Buches übersetzt Inga Meincke Grundtvigs Wahlaufruf mit Anklängen an das Deutschlandlied »Dänemark ... über alles« (S. 15 u.ö.). 
Der zweite kritische Ansatz der Grundtviginterpretation Inga Meinckes bezieht sich auf Grundtvigs Begriff der Aufklärung, der den platten Rationalismus bekämpft und das Lebendige Wort einem falschen Vernunftglauben entgegenstellt. Hinter freiheitlicher Rhetorik tun sich autoritäre Tendenzen auf, die Rede von der lebendigen Wechselwirkung verdeckt nur die totalitäre Tendenz. Grundtvig ist ein visionärer Gegenaufklärer, der keinen Widerspruch duldet:

Grundtvigs Theorie vom lebendigen Wort ist so entgegen landläufiger Meinung kein Versuch (unter zahlreichen vergleichbaren des 19. Jahrhunderts) zur Emanzipation der - geistlichen wie weltlichen - Laien. Sie verschiebt die Deutungshoheit von einer Vielzahl von Fachleuten, die äußerlichen, nachprüfbaren Kriterien von Wissenschaftlichkeit und damit wechselseitiger Konkurrenz unterworfen sind, Fachleuten, zu denen prinzipiell jeder gehören kann, auf den zum Dechiffreur der Welt bestellten Einen, der vorgibt, bloßes Medium gegebener Wahrheit zu sein. Durch Grundtvig spricht die Sache, für die er spricht, die Kirche, die Geschichte, der Heldengeist, Dänemark und Gott ... Grundtvigs Sprechen ist Verkündigung, die Kanzel eine 'prophetische Plattform' und 'theologische Werkstatt', ein geistiges Experimentierfeld, auf dem - ohne das Risiko der Gegenrede - jede 'Entdeckung' vor ihrer Verweltlichung auf ihre Wirkung hin überprüft werden kann (S. 312).

Grundtvig denkt, so die These, reaktionär und autoritär: Däne ist, wen Grundtvig dafür bestimmt. Grundtvigs Zwiespältigkeit in bezug auf die französische Revolution ist nicht, wie man gemeint hat, eine zunehmend optimistischere Lebenseinstellung Grundtvigs, sondern der kritische Punkt seiner Hermeneutik: die Reklamation des einzig legitimen Blicks auf die Welt, die Behauptung absoluter Immanenz, die das kritische Denken prinzipiell zurückweisen muß (S. 187).

Inga Meincke geht hart ins Gericht mit der Rezeptionsgeschichte Grundtvigs, die die totalitären Züge des Grundtvigschen Denkens »psychologisiert, ästhetisiert, karikiert, ignoriert oder auch abgeschwächt bejaht « und damit verharmlost (S. 73.). Gegen diese verharmlosende Rezeption wendet sich das Buch, indem es das Weltbild Grundtvigs ernst nimmt und dessen totalitäre Tendenzen aufdeckt. Man darf Grundtvig nicht verharmlosen, man muß ihn beim - lebendigen - Wort nehmen.

$\mathrm{Daß}$ es bedenkliche »nationalistische« und totalitäre Tendenzen bei Grundtvig gibt, läßt sich schwer bestreiten - wohl auch nicht daß es Tendenzen in der Grundtvigrezeption gibt, dies zu verdrängen oder zu verharmlosen. Die Frage ist sozusagen nicht, $o b$ es diese Tendenzen gibt, sondern wie man damit umgeht und wie man sie einordnet. Es ist verdienstvoll, daß Inga Meincke das offen ausspricht.

Dennoch befriedigt die These Inga Meinckes nicht ganz, die kurzerhand die ganze Wirkungsgeschichte als »landläufige Meinung « und Mißverständnis abtut. Man muß, das ist mein Einwand, die temporale Differenz hermeneutisch in Betracht ziehen und 
darf Grundtvig (wie auch andere) nicht einfach an heutigen Maßstäben messen. Inga Meincke zeigt Aspekte des Grundtvigschen Denkens, die uns heute fremd sind. Das ist verdienstvoll. Auch ist ihr zuzustimmen, daß man diese Seiten nicht einfach im apologetischen Interesse weginterpretieren darf. Aber deshalb ist die Aufgabe einer Aktualisierung und damit Umiterpretation bzw. Neuinterpretation noch nicht illegitim. Mag sein, daß Grundtvigs Reden von Muttersprache und Volk von Grundtvig viel enger als eine Metaphysik von der Überlegenheit dänischer Sprache und Kultur gemeint war, die Wirkungsgeschichte - gerade auch die internationale in der Heimvolkshochschulbewegung - zeigt aber, daß es durchaus legitim sein kann, Grundtvig mehr universell zu interpretieren. Mag sein, daß Grundtvig mit seinem Gedicht Mensch zuerst in Wirklichkeit Däne zuerst gemeint hat, aber es muß erlaubt sein, gerade dieses Gedicht auch universell zu interpretieren. Und daß das schöne Pfingstlied Var I ikke Galilaeer vor allem davon spricht, daß der Geist in der dänischen Muttersprache besonders wehe (V. 3, siehe S. 74, Anm. 311), mag vielleicht die Meinung Grundtvigs gewesen sein, macht aber eine universelle Deutung dieses Liedes nicht unmöglich. Muß nicht jede aktualisierende Interpretation, sei dies nun Luther, Kierkegaard oder Grundtvig, unterscheiden zwischen dem, was zeitbedingt ist an einem Autor und fremd, und dem, was sich aktualisieren läßt? Dabei ist auch bei einer mehr immanenten Grundtviginterpretation zu beachten, welchen Stellenwert die von der Autorin aufgezeigten problematischen Aspekte bei Grundtvig haben. Man darf die »totalitären« Aspekte bei Grundtvig nicht weginterpretieren - man darf sie aber auch nicht überinterpretieren, als habe Grundtvig immer nur die Überlegenheit dänischer Kultur und Sprache im Kopf, wenn er von Volk und Muttersprache redet. Man läuft dann auch Gefahr, die progressiven Seiten des grundtvigschen Erbes aus den Augen zu verlieren. So eindeutig ist die Sache vermutlich nicht: Auch die »linke« und progressive Grundtvigrezeption kann sich auf Grundtvigtexte berufen.

Wie dem auch sei: Trotz der These des Buches vom totalitären und autoritären Charakter des Grundtvigschen Werkes bin ich der Auffassung, daß Grundtvig heute Widerspruch und Kritik nicht nur ertragen kann, sondern auch braucht. Grundtvig ist vermutlich mit kritischer Aufmerksamkeit mehr gedient als mit platter Apologetik. Deshalb: Ein wichtiges und verdienstvolles Buch!

\section{»Efterklang« som tolkningsnøgle}

\section{Af Kim Arne Pedersen}

Anders Holm:Historie og Efterklang. En studie i N.F.S. Grundtvigs tidsskrift DanneVirke. Odense Universitetsforlag 2001. 139 sider. Pris: 175 kr.

Grundtvig-forskningen har i de senere år næsten umærkeligt oplevet en væsentlig ændring, når det gælder tilgangen til det store forfatterskab. Hvor den tidligere forskning overvejende forholdt sig positivt til Grundtvigs tankeverden, har man fra slutningen af 1990-erne kunnet opleve en langt mere kritisk holdning, knyttet til dels 